\title{
Soil Anxiety Effects Influencing Symbiotic Microbial Activity in the Soil
}

\author{
Wubayehu Gebremedhin \\ Ethiopian Institute of Agricultural Research, Fogera National Rice Research and Training Center, \\ Woreta, Ethiopia
}

\begin{abstract}
The soil environment is under a constant state of change and can be relatively stressful for both macro- and microorganisms. Soils represent one of Earth's most productive ecospheres, accounting for a majority of primary and successional productivity. Consequently, microbes, plants, and other soil inhabitants have evolved to adapt to the ever changing and often inhospitable soil environment. Based on the above facts, in this paper we can speak of stress factors originating in the soil. In many cases these factors are resulted from biotic factor which includes the living components such as plants, animals, and microbes which has its own energy and material fluxes. The second major soil stress factors that include potentially adverse effects of acidity, salinity, drought, flooding, waterlogging, nutrient deficiency, high temperature and are abiotic or an environmental factor in the soil. These factors interrupts, restricts, or harmfully accelerates the normal metabolic processes of a plant and symbiotic microorganism.
\end{abstract}

Keywords: Stress; Soil; Rhizobia; Plant

DOI: $10.7176 / \mathrm{JEES} / 9-12-02$

Publication date: December $31^{\text {st }} 2019$

\section{Introduction}

The soil environment is under a constant state of change and can be relatively stressful for both macro and microorganisms. The fluctuations have been recorded in soil $\mathrm{pH}$, nutrient availability, temperature, and water status. Therefore, the variation which occurs in different soil characteristics prominently influence the growth, survival and metabolic activity of soil microorganisms and plants, and their ability to enter into symbiotic interactions. In the plant- microbe, symbiotic association the nodD gene can be viewed as a global regulatory gene which, together with plant flavonoid-signal molecules, activates transcription of other inducible nodulation genes (Long, 2001). The flavonoid nod-gene inducers are specific for a particular legume-Rhizobium interaction and their production is influenced by environmental variables, like plant fertility, $\mathrm{pH}$, and nod factors (Schmidt et al., 1994). Repressor proteins also play a role in nod-gene regulation (Stacey et al., 2002).

The two common consequences of inadequate soil management due to fragile soil structure, erosion, low soil organic matter and inappropriate farming technologies are nutrient depletion and soil acidification (Giller and Wilson, 1993). Plant development and successful crop production require proper soil conditions, including adequate water and nutrient supply. Unfavorable soil conditions (environmental stress (Takeoka Y et al., 1992; Bohnert et al., 1995) salinity and/or sodicity (Bauder J.W. and Brock T.A. 1992; Qadir et al., 1996), inadequate nutrient supply have an adverse effect on the life of the plants, sometimes seriously hindering their effective production. Despite this situation, soils represent one of Earth's most productive ecospheres, accounting for a majority of primary and successional productivity. Consequently, microbes, plants, and other soil inhabitants have evolved to adapt to the ever changing and often inhospitable soil environment.

Based on the above facts, we can speak of stress factors originating in the soil; that is, such unfavorable soil conditions which cause, or contribute to, the stress factors that plants and crops are exposed to. Stress is here considered to be any external factor that results in a less than optimal growth rate (i.e., any factor that interrupts, restricts, or harmfully accelerates the normal metabolic processes of a plant). It is impossible to list all or most of such factors in a short introductory review. Therefore, I limit the range of this manuscript objective to a highlight of soil stress factors behavior and its function in nature and production as well as to an outline of some of the most serious factors originating in stress affected soils in relation to soil microbial activity. For more in-depth information regarding stress affected soils, the readers are referred to the more comprehensive available sources.

\section{Biotic factors}

Agricultural expansion impacts and fragments natural ecosystems; human activities have already transformed $33-50 \%$ of the earth's surface. Consequences include extinction of some plant species and reduction in the population size, diversity, and function of others (Young and Clarke, 2000). Differing in colony morphology, DNA finger prints, rates of $\mathrm{N} 2$ fixation, and strain competitiveness (Ferreira et al., 2000; Galli-Terasawa et al., 2003; Santos et al., 1999). Hungria and Vargas (2000) suggest that genetic instability is increased by the high temperature/acid soil conditions, and note that superior genetic stability is essential for any strain recommended for use in commercial inoculants in Brazil. 
Legumes and cereals are often intercropped, a traditionally to enhance land-use efficiency and reduces farmer dependence on a single plant species (Wooley et al., 1991). Given the proximity over time of cereal and Rhizobium, it is not surprising that a number of these organisms have acquired the ability to act as endophytic organisms.

However, the soil includes different phases (solid, liquid, gaseous), living and nonliving substances, plants, animals, and microbes and has its own energy and material fluxes. Therefore, it can be considered an ecosystem in itself. In this respect, when speaking of soils versus their plant cover, we can consider the soils of a given location as the basis, ladder, and foothold, a well-defined plant cover develops and very often the soil properties promote or limit the living conditions of certain plant species or associations.

Different researches reported that soils are affected due to the direct biological interference where high electrolyte contents, extreme $\mathrm{pH}$ conditions, over flooding and nutrient depletions limit the development of the majority of plants and it retards biological nitrogen (N2) fixation is a critical and key unenthusiastic impact in sustainable land management, where $\mathrm{N}$ is the nutrient that most frequently limits crop production.

\section{Abiotic factors}

The abiotic factor is one of the most important challenges facing on soil fertility. Abiotic stress can persistently limit the nutrient availability, microbial diversity and agricultural productivity over large areas and extreme events can lead to total crop production failures. Abiotic stresses adversely affect the livelihoods of individual farmers and their families as well as national economies and food security. The major soil stress factors include potentially adverse effects of acidity, Salinity, Drought, Flooding, waterlogging, Nutrient deficiency, High temperature and Low temperature.

\subsection{Soil acidity}

In the worldwide, more than $1.5 \mathrm{Gha}$ of acid soils limit agriculture production (Von Uexkull $\mathrm{H}$ and Mutert E. 1995). Here there is a range of effects of soil $\mathrm{pH}$ on rhizobia, but relatively few grow and survive well below $\mathrm{pH}$ values of 4.5-5.0. Competitive interactions have been shown to be influenced by soil $\mathrm{pH}$. The bradyrhizobia are more acid tolerant than the rhizobia. The influence of soil $\mathrm{pH}$ on the behavior of rhizobia in soils can be dramatic.

Generally, S. fredii is more competitive than B. japonicum in soybean nodulation in neutral soils in Spain, but $\mathrm{B}$. japonicum USDA 110 out- competed $\mathrm{S}$. fredii in soil at $\mathrm{pH}$ 4.9. The fact that $\mathrm{R}$. etli is more competitive than R. tropici in nodule formation with beans. Many rhizobia from acid soils are sensitive to acidity. They suggested that soil microniches protect these rhizobia from extremes of soil $\mathrm{pH}$. So, merely isolating a rhizobial strain from root nodulesof plants grown in acid conditions does not guarantee that the isolated strain will be acidresistant (Graham, 1992). But the recent studies showed this acid and alkaline resistant could be related to local adaptation since small farming is being done at the salinity soils of Ethiopia where chickpea is commonly grown along with intercropping of wheat which is highly beneficial for the farmers (Wubayehu G et al., 2018) as well as the rhizobial strains could grow well in wide range of $\mathrm{pH}$ from acid to alkaline i.e. 5-9.5 and this was consistent with chickpea production on calcareous soils in India (Rhitu et al., 2012).

Furthermore, metals, such as $\mathrm{Al}, \mathrm{Cu}$, and $\mathrm{Mn}$ that become more soluble at lower $\mathrm{pH}$, may also secondarily contribute to the inhibition of the growth and persistence of rhizobia in acid soils nutrients. Tolerance to acid conditions in rhizobia is often correlated to the strains ability to maintain an internal $\mathrm{pH}$ approaching neutrality ( $\mathrm{pH}$ 7.2-7.5). This ability has been suggested to be due to proton exclusion enhanced cytoplasmic-buffering capacity. the presence of acid-shock responses, the presence of glutathione. Although the microsymbiont appears more $\mathrm{pH}$ sensitive than the host partner acidity also influences both the growth of the legume plant and the infection process interestingly, nodulated legumes appear more sensitive to metal toxicity by $\mathrm{Mn}$ and $\mathrm{Al}$ than to their $\mathrm{N}$-fed control counterparts.

Soil acidity affects early steps in the infection process, including the exchange of molecular signals between symbiotic partners and attachment to the roots. Release of nod-gene inducers by soybean and common bean roots was less at pH 4.5 than at pH 5.8 (Hungria and Stacey, 1997), with some nodulation genes, including nodA, switched off as the pH falls (Richardson et al., 1988a,b). In addition, McKay and Djordjevic (1993) have reported that low $\mathrm{pH}$ can affect the production and excretion of nodulation factors in strains of $R$. leguminosarum bv. trifolii. Other stages of nodule establishment and function are also impacted by acidity, as is the growth of the host plant (Graham, 1981; Munns, 1986).

Recently, using molecular techniques and proteomics, Glenn and colleagues have shown that rhizobial genes, such as actA, actP, exoR, lpiA, actR, actS, and phrR, are essential for growth at low $\mathrm{pH}$.

\subsection{Soil Salinity}

Salinity and sodicity problems are common in arid and semiarid regions, where rainfall is insufficient to leach salts and excess sodium ions out of the rhizosphere (Miller and Donahue, 1990). These problems are present in 
nearly every irrigated area of the world and also occur on non irrigated croplands and rangelands. Thus, virtually no land is immune from salinization. Therefore, for sustaining life on earth, control of these problems and finding new ways to utilize these extensive saline and sodic soils and water resources, at least for agricultural purposes, are vital and urgent.

In nature, usually particular plant species grow on specific soils. Thus, specific relationships exist between a particular soil and the vegetation cover of that specific soil. According to an early Food and Agriculture Organization (FAO) study (Massoud, 1974), salt-affected soils occupy 7 percent of the world land area, and salinity is also a problem that is increasing rapidly (Pessarakli, 1999), having more than doubled in the past two decades. It is estimated that the world is losing at least 10 ha of arable land every minute and 3 ha of this is lost by salinization. In this way, $1.6 \mathrm{mha}$ of arable land is lost every year.

Since beneficiary microorganisms are available in all arable lands in the globe edaphic factors have long been known to influence soil microbes and a number of reviews have already documented the importance of different edaphic stresses to rhizobial persistence, subsequent nodulation, and nitrogen fixation by (El Sheikh, 1998; Miller and Wood, 1996; Zahran, 1999) indicates giving an emphasis will decide the productivity fate of these huge area in the world.

\subsection{Soil Water Stress}

Soil water influences the growth of soil microorganisms through processes of diffusion, mass flow, and nutrient concentration is related to soil pore space. Internal pore spaces are more favorable environments for the growth of rhizobia and most soil microbes. Soil-water content also directly influences the growth of rhizosphere microorganisms, like rhizobia, by decreasing water activity below critical tolerance limits and indirectly by altering plant growth, root architecture, and exudations. Usually, at matrix water potentials of -0.5 to $-1.5 \mathrm{MPa}$, growth and nitrogen fixation are affected in tropical areas. The low availability of soil water would be aggravated by the removal of deepl-rooted vegetation and the conversion of natural forests or savannas to crop production or pasture, with increased runoff and evaporation. Poor nodulation of legumes in arid soils is likely due to decreases during the dry season.

Water activity (Aw) and water potential (z) values are parameters often used for describing water relations with respect to microorganisms. Rhizobia vary widely in their tolerance to water stress, and there is correlation to taxonomic criteria and phylogenetic relationships. However bradyrhizobia suggested being more resistant to water stress mostly by the intracellular accumulation of inorganic and/or organic solutes. Water stress affects rhizobial survival, growth and population structure in soil, the formation and longevity of nodules, synthesis of leghaemoglobin and nodule function. Furthermore, severe stress may lead to irreversible cessation of N2 fixation (Sprent, 1971; Vincent, 1980; Walker and Miller, 1986; Venkateswarlu et al., 1989; Guerin et al., 1991). In rhizobia (and all bacteria), both cell membranes and walls play a pivotal role in tolerance to water-potential stress.

Many microbes, including rhizobia, accumulate compatible solutes, such as amino acids and salts as a means to equilibrate internal and external osmotic concentrations. Osmoregulation is a complex problem for rhizobia because they must be able to adapt to unfavorable and changing environmental conditions, as well as to osmotic- stress conditions associated with the infection process itself and life in the nodule.

\subsection{Soil temperature stress}

Temperature has a marked influence on survival and persistence of rhizobial strains in soils. rhizobia from the hot dry Sahel-savannah of West Africa grow at $37^{\circ} \mathrm{C}$, and more than $90 \%$ of the strains isolated from this region grew well to $40^{\circ} \mathrm{C}$. The influence of temperature on rhizobia appears to be both strain and soil dependent. Bradyrhizobium sp. (lupins) was less susceptible than $R$. leguminosarum bv. trifolii to high soil temperatures, but addition of montmorillonite and illite remediated this problem in sandy soils (Marshall, 1964). Soil temperature also greatly influences competition for nodulation. This effect due to a temperature-induced delay in nodulation or the restriction of nodules to the sub-surface region (Munns et al., 1977).

'The highest and lowest temperature extremes influence the soil temperature on the growth and survival of rhizobia, however rhizobia isolated from temperate regions often survive at $4 \mathrm{oC}$, little growth occurs at this temperature (Trinick, 1982). The symbiosis itself is sensitive to low temperatures; cooler root-zone temperatures limit nodulation and nitrogen fixation in the soybean-B. japonicum symbiosis (Zhang et al., 1995). However, excessive temperature shock has been shown to cure plasmids in fast-growing strains and some strains, which were isolated from high-temperature environments, have a Fix-phenotype.

Effective high- temperature $(40 \mathrm{oC})$ tolerant rhizobia that are capable of nodulating and fixing nitrogen with Phaseolus vulgaris (Hungaria et al., 1993) acacia (Zerhari et al., 2000) and prosopis (Kulkarni and Nautiyal, 1999) has been reported. The high-root temperature has also been shown to influence infection, N2- fixation ability, and legume growth. It appears that every legume/Rhizobium combination has an optimum temperature relationship, which is around $30 \mathrm{oC}$ for clover and pea, between $35-40 \mathrm{oC}$ for soybean, peanut and cowpea, and 
between 25-30oC for common bean (Michiels et al., 1994).

Exposure of both symbiotic partners to the extreme temperature above or below these critical temperatures impairs infection, nodulation, nodule development, and general nodule functioning as well as both plant growth and productivity. High soil temperatures also restrict nodulation to sub-surface regions where cooler temperatures prevail. Nevertheless, elevated temperature directly influences the production or release of nodgene inducers from soybean and bean it alters nodule functioning due to leghemoglobin synthesis, nitrogenase activity, and hydrogen evolution, and, besides, hastens nodule senescence although, heat-shock proteins have been found in rhizobia.

\section{Conclusion}

It is impossible to list all stress factors that influence the microbial activity, according to its behavior, it can be summarized in to biotic and abiotic factors. Biotic factors mainly, related to the crop management system, biodiversity and direct biological interferences. Beyond biotic factors the major stress factors which have a potentially adverse effect are the abiotic factors. These include soil acidity, salinity, waters stress and temperature are the major influences.

\section{Acknowledgement}

All authors cited in this review are highly acknowledged.

\section{References}

Bauder J.W.and Brock T.A. (1992). Crop species amendment and water quality effects on selected soil physical properties. Soil Sci Soc Am J 56(4):1292-1298.

Bohnert H.J., Nelson D.E.and Jensen R.G. (1995). Adaptations to environmental stresses. Plant Cell 7(7):10991111 ,

El Sheikh, E. A. E. (1998). Effects of salt on rhizobia and bradyrhizobia: A review. Ann. Appl. Biol., 132, 507524.

Ferreira, M. C., Andrade, D. D., Chueire, L. M. D., Takemura, S. M., and Hungria, M. (2000). Tillage method and crop rotation effects on population sizes and diversity of bradyrhizobia nodulating soybean. Soil Biol. Biochem., 32, 627-637.

Galli-Terasawa, L. V., Glienke-Blanco, C., and Hungria, M. (2003). Diversity of a soybean rhizobial population adapted to a Cerrados soil. World J. Microbiol. Biotechnol., 19, 933-939.

Giller, K.E., Wilson, K.J., 1993. Nitrogen Fixation in Tropical Cropping Systems. CAB International,Wallingford, UK, $313 \mathrm{pp}$.

Graham, P.H., 1981. Some problems of nodulation and symbiotic nitrogen fixation in Phaseolus vulgaris: a review. Field Crops Res. 4, 93-112.

Guerin, V., Pladys, D., Trinchant, C., Rigaud, J.M., 1991. Proteolysis and nitrogen fixation in faba-bean (Vicia faba) nodules under water stress. Physiol. Plant 82, 360-366.

Hungria, M., and Vargas, M. A. T. (2000). Environmental factors affecting N2 fixation in grain legumes in the tropics, with an emphasis on Brazil. Field Crops Res., 65, 151-164.

Hungria, M., Franco, A. A., and Sprent, J. I. (1993). New sources of high-temperature tolerant rhizobial for Phaseolus vulgaris (L.). Plant Soil, 149, 103-109.

Hungria, M., Stacey, G., 1997. Molecular signals exchanged between host plants and rhizobia: basic aspects and potential application in agriculture. Soil Biol. Biochem. 29, 519-830.

indigenous rhizobia nodulating Chickpea in India. Indian J Extal Biol. 50: 340-350.

Kulkarni, S., and Nautiyal, C. S. (1999). Characterization of high temperature-tolerant rhizobia isolated from Prosopis juliflora grown in alkaline soil. J. Gen. Appl. Microbiol., 45, 213-220.

Long SR (2001). Genes and signals in the Rhizobium-legume symbiosis. Plant Physiol., 125: 69-72.

Marshall, K. C. (1964). Survival of root nodule bacteria in dry soils exposed to high temperatures. Aust. J. Agric. Res., 15, 273-281.

Massoud., F. I.1974.salinity and alkalinity as soil degradation hazards.FAO/UNDP,Expert consultation on soil degradation.FAO Rome.p. 21

McKay, I.A., Djordjevic, M., 1993. Production and excretion of nod metabolites by Rhizobium leguminosarumbiovar trifolii are disrupted by the same environmental factors that reduce nodulation in the ®eld. Appl. Environ. Microbiol. 59, 3385-3392.

Michiels, J., Verreth, C., and Vanderleyden, J. (1994). Effects of temperature on bean-nodulating

Miller, K. J., and Wood, J. M. (1996). Osmoadaptation by rhizosphere bacteria. Annu. Rev. Microbiol., 50, 101136.

Munns, D. N., Fogle, V. W., and Hallock, B. G. (1977). Alfalfa root nodule distribution and inhibition of nitrogen fixation by heat. Agron. J., 69, 377-380. 
Munns, D.N., 1986. Acid soil tolerance in legumes and rhizobia. Adv. Plant Nutr. 2, 63-91.

Nitrogen Fixation, Vol. II. Symbiotic Associations and Cyanobacteria. University Park Press, Baltimore, MD, pp. 103-129.

Pessarakli, M. (1999) Response of green beans (Phaseolus vulgaris L.) to salt stress. In: Pessarakli, M (ed). Handbook of Plant and Crop Stress 2ed.MARCED LEKKERIN, C.E.E.U.U., pp827-842.

Qadir M., Qureshi R.H., Ahmad N. and Ilyas M. (1996). Salt-tolerant forage cultivation on a saline-sodic field for biomass production and soil reclamation. Land Deg Dev 7(2):11-18,.

Rhitu R, Prasanta KD, Trilochan M, et al. (2012). Phenotypic and molecular characterization of

Rhizobium strains. Appl. Environ. Microbiol., 60, 1206-1212.

Richardson, A.E., Djordjevic, M.A., Rolfe, B.G., Simpson, R.J., 1988a. Effects of pH, Ca and Al on the exudation from clover seedlings of compounds that induce the expression of nodulation genes in Rhizobium trifolii. Plant Soil 109, 37-47.

Richardson, A.E., Simpson, R.J., Djordjevic, M.A., Rolfe, B.G., 1988b. Expression of nodulation genes in Rhizobium leguminosarum biovar trifolii is affected by low $\mathrm{pH}$ and by $\mathrm{Ca}$ and $\mathrm{Al}$ ions. Appl. Environ. Microbiol. 54, 2541-2598.

Schmidt PE, Broughton WJ, Werner D (1994). Nod factors of Bradyrhizobium japonicum and Rhizobium sp. NGR 234 induce flavonoid accumulation in soybean root exudates. Mol. Plant Microbe Interact., 7: 384390.

Sprent, J.I., 1971. Effects of water stress on nitrogen fixation in root nodules. Plant Soil (Spec. Vol.), 225-228

Stacey G, Finan M, O’Brian MR (2002). Signal exchange during the early events of soybean nodulation. Nitrogen Fixation Global Perspectives (pp. 118-122). Wallingford, UK: CABI Publishing.

Takeoka Y., Al-Mamun A., Wada T., and Kaufman P.B. (1992).Developments in Crop Science. Vol. 22. Reproductive Adaptation of Rice to Environmental Stress. Tokyo: Japan Science Society Press. New York: Elsevier,.

Trinick, M. J. (1982). Biology. In W. J. Broughton (Ed.), Nitrogen Fixation, Vol. 2 Rhizobium (pp. 76-146). Oxford, UK: Clarendon Press.

Venkateswarlu, B., Maheshwari, M., Saharan, N., 1989. Effects of water deficit on N2(C2H2) fixation in cowpea and groundnut. Plant Soil 114, 69-74.

Vincent, J.M., 1980. Factors controlling the legume \pm Rhizobium symbiosis. In: Newton, W.E., Orme-Johnson, W.H. (Eds.),

Von Uexkull H and Mutert E. (1995). Global extent, development and economic impact of acid soils. Plant Soil. ;171:1-15. doi: 10.1007/BF00009558. [CrossRef] [Google Scholar.

Walker, D.W., Miller Jr., J.C., 1986. Influence of water stress on nitrogen fixation in cowpea. J. Am. Soc. Hort. Sci. 111, 451-458.

Wooley, J., Lepiz, R., Aquinas-Portes y Castro, T., and Voss, J. (1991). Bean cropping systems in the tropics and subtropics and their determinants. In A. van Schoonhoven and O. Voysest (Eds.), Common beans: Research for crop improvement (pp. 679-706). Cali, Colombia: CIAT.

Young, A. G., and Clarke, G. M. (2000). Genetics, demography and viability of fragmented populations. Cambridge, UK: Cambridge University Press (438 pp.).

Zahran, H. H. (1999.) Rhizobium legume symbiosis and nitrogen fixation under severe conditions and in an arid climate. Microbiol. Mol. Biol. Rev., 63, 968-989.

Zerhari, K., Aurag, J., Khbaya, B., Kharchaf, D., and Filali-Mattouf, A. (2000). Phenotypic characteristics of rhizobia isolates nodulating Acacia species in the arid and Saharan regions of Morocco. Lett. Appl. Microbiol., 30, 351-357.

Zhang, F., Lynch, D. H., and Smith, D. L. (1995). Impact of low root temperature in soybean [Glycine max (L. Merr.)] on nodulation and nitrogen fixation. Environ. Exper. Bot., 35, 279-285. 